\title{
Editorial
}

\section{Nuevos modelos de familia y desarrollo psíquico de los niños}

Publicado en Internet:

28-marzo-2019

Ángeles Torner Hernández: angelestorner@adipsicoterapia.com

\author{
Ángeles Torner Hernández \\ Psicóloga clínica. Centro de Atención al Desarrollo Integral (ADI). Madrid. España.
}

\begin{abstract}
¿ L La trasformación de la familia en el mundo occidental supone uno de los mayores cambios en los últi-
- Filiaciones

- Identidad subjetiva

- Parentalidad mos 50 años. Se ha pasado de la familia nuclear, como modelo casi único, a una multiplicidad de formas de organización familiar. Estos cambios han hecho más compleja la estructuración de la identidad de los hijos. Cada niño necesitará integrar los efectos imaginarios que cada una de estas configuraciones familiares generan, para lo que necesitará la ayuda del entramado familiar y social que le rodea.
\end{abstract}

\section{New family models and children's psychic development}

\begin{tabular}{|c|c|}
\hline 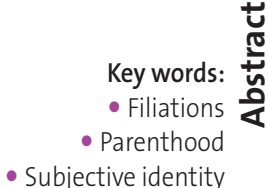 & $\begin{array}{l}\text { The transformation of the family in the western world is one of the biggest changes in the last } 50 \text { years. } \\
\text { It has gone from the nuclear family, as an almost unique model, to a multiplicity of family organization } \\
\text { forms. These changes have made the structuring of children's identity more complex. Each child will } \\
\text { need to integrate the imaginary effects that each of these family configurations generate, for which he } \\
\text { will need help of family and social network that surrounds him. }\end{array}$ \\
\hline
\end{tabular}

La familia actual se ha hecho más compleja. Madre y padre adquieren carácter plural: madre o padre biológico, padre dador de esperma, madre sustituta, madre de crianza o de afecto, etc., y en algunas formas de reproducción o de acceder a ser padres siempre va a estar presente un tercero, dador de semen, de óvulo, de útero, padres biológicos, etc. El proyecto de hijo ya no es solo un proyecto de pareja, sino también un proyecto individual; la globalización ha favorecido el aumento de la adopción internacional y también se ha hecho más compleja por los sucesivos divorcios e hijos de diferentes parejas, con vínculos fraternos varios, filiaciones cambiantes, múltiples padres o madres.
Una familia la constituyen dos generaciones con cierta estabilidad en el ejercicio de sus funciones, lo que quiere decir que en la medida en que haya un adulto capaz de cuidar a un niño y un niño capaz de ser cuidado por un adulto podremos hablar de familia'.

No existe un modelo familiar idóneo para un buen desarrollo psíquico, y no se puede adjudicar a priori patología a un niño ni a sus padres por constituir un modelo de familia diferente.

Pero podemos pensar en una serie de criterios que van a favorecer un desarrollo adecuado:

- Que la estructura familiar sea clara y que las funciones de sus integrantes estén consensuadas y aceptadas entre los adultos. 
- Ser padres es un proceso (parentalidad) que se diferencia de la reproducción biológica y del parentesco, y pone el acento en las funciones parentales, tanto materna como paterna, sin jerarquizarlas ni especificar géneros. Llegar a ser padres es efecto de un largo trabajo psíquico interno y relacional. Se inicia con el deseo de un hijo, se desarrolla durante el embarazo con las representaciones que ambos padres van a crear en su mente pensando en su bebé, preparando el espacio psíquico que lo acogerá y que al nacer lo confrontará a esas representaciones mentales que se han ido construyendo. Este punto de vista permite pensar en la existencia de estas funciones sin que implique necesariamente la presencia real de un padre o una madre, (en el caso de las familias monoparentales, pero no solo en ellas, ambas funciones van a tener que ser ejercidas por el mismo adulto).

- Otro criterio es la cualidad de esas funciones parentales en cada familia. El psiquismo del niño se organiza en el encuentro privilegiado con quien ejerza la función maternal: adulto totalmente disponible y empático que pueda satisfacer sus necesidades emocionales y físicas, favoreciendo mediante su propia capacidad mentalizadora que el bebé pueda dar sentido a las sensaciones experimentadas. Ello hace imprescindible la disponibilidad emocional y de tiempo para "maternar" y favorecer el desarrollo en el bebé de su organización relacional. Esta función incluye también a otros que son soporte para hacerla posible y también son parte de ella. El modelo vincular de este encuentro, su regularidad y seguridad, su capacidad de contener los malestares del niño, etc., construirá el modo de relación del niño consigo mismo y con los demás.

- Esta disponibilidad del adulto tan necesaria para el bebé es preciso que vaya abriéndose progresivamente a otro adulto y a otros intereses. Las experiencias de satisfacción e insatisfacción que el bebé vive regularmente, ligadas a la presencia o ausencia tolerable del adulto que "materna", irán permitiendo una cierta diferenciación.

- La función paterna, como función simbólica de tercero, favorecerá salir de la relación fusional, y acceder a la capacidad de simbolización (la capacidad del niño para jugar, evocar objetos y personas que no están presentes), pero para que sea efectiva tiene que ser reconocida por el otro adulto. Diferenciación y límite que incluye a todos, adultos y niño, y cuya interiorización será el soporte de la autoridad, lo que hará posible tolerar la frustración y la espera y la salida a lo social. El acceso a la simbolización permite que aparezcan nuevas discriminaciones, la diferencia de generaciones y de sexos, que contribuirán a la estructuración del psiquismo.

Este adulto en función paterna es muy importante también en el cuidado y crianza del niño pequeño, lo que favorecerá su compromiso y presencia activa en todo el desarrollo.

Estas funciones han sido "naturalmente desempeñadas" por la madre o el padre, pero no tiene que ser así necesariamente. Las habilidades de cuidar a los bebés son semejantes, ambos tienen capacidades que los hombres abandonan antes y las mujeres asumen como función propia.

Cada mujer y cada hombre ejercerán una y otra de las funciones parentales de acuerdo con su personalidad, su historia, y seguramente también dependiendo de su condición de hombre o mujer, y de los condicionantes culturales adscritos a uno $u$ otro género. El psiquismo de cada hombre y cada mujer está constituido por identificaciones tanto masculinas como femeninas, con el padre y la madre y sus ideales, pero también a otras figuras masculinas y femeninas que han sido significativas.

El deseo de un hijo implica un deseo de vida, de transcendencia, y de modo simbólico, el embarazo y el hijo posteriormente permiten un estado de completud, la capacidad de crear a un semejante, prueba de fecundidad y potencia, lo que ayuda a exorcizar nuestra condición humana de seres con carencias. Dependiendo de la estructura psíquica de cada padre-madre, ese hijo puede ser buscado por identificación con la función parental de sus propios padres, o ser buscado, por el contrario, para una negación de las propias carencias vitales.

Así, desear ser padre o madre puede ser un deseo tanto saludable como patológico, y para algunos adultos, puede llegar a convertirse en una necesidad tiránica cuando no ha sido posible hacer el duelo del "deseo de hijo"2.

- Si un eje del proceso de parentalidad es convertirse en padres, otro es la filiación, el reconocerse como hijo de sus padres y aceptar su herencia. 
Las preguntas que todo niño necesita hacerse cuando va creciendo, "iquién soy?", "de dónde vengo?", le llevan a querer saber cuál ha sido el deseo de los padres biológicos, deseo de los padres de crianza o de afecto hacia él, al enigma de la sexualidad entre ellos y a la elaboración de su propia novela familiar. Resolver estos interrogantes le permitirá incluirse y pensarse dentro de una historia familiar.

- Cuando es posible y elaborable, el niño tiene derecho a conocer su historia, conocer la identidad de sus progenitores y las circunstancias de su concepción.

Hablar de los orígenes para muchos padres es casi imposible, porque significa asumir la diferencia entre maternidad o paternidad biológica y de afecto, lo que les supone una herida narcisista insoportable. Se instala así a veces la necesidad del secreto con sus efectos traumáticos. Cuando los padres no pueden evocar ni hablar de las emociones ligadas a los orígenes, no es posible que los hijos lo puedan pensar ni preguntar, lo que los lleva posiblemente a la imposibilidad de simbolizarlo e integrarlo en su psiquismo.

Para el niño, llegar a tener una identidad propia va unida tanto al proceso de separación y construcción de un yo propio y diferente a otro, como a conseguir sentirse parte de, quedar inscrito dentro de una filiación.

Actualmente hay mayor complejidad en la estructuración de la identidad, y los criterios que determinan la filiación son múltiples: los niños cambian de familias y de modalidades de estructuración de estas (pueden pasar de formar parte de una familia tradicional, a una familia monoparental u homoparental, o con hermanos nacidos en otras culturas, etc.), cambian de lenguas, y pueden tener más de una identidad.

Todas estas configuraciones familiares múltiples provocan efectos imaginarios, que cada niño tendrá que elaborar, para lo que necesitará la ayuda de los adultos que forman su trama familiar y social, para que ellos encuentren la posibilidad de imaginar sobre los orígenes y poner palabras.
Debido a la fragilidad psíquica y física de estas etapas, es muy necesario para cualquier nueva familia contar con una ayuda protectora y no invasiva, pero más cuando las condiciones de acceso a convertirse en padres han sido costosas emocionalmente. Cómo socialmente podamos integrar todas estas nuevas estructuras familiares redundará en una mayor capacidad parental de los adultos.

Factores que promueven un desarrollo adecuado:

- Que los padres puedan aportar seguridad y continuidad en los cuidados por parte de adultos confiables, sea el modelo familiar que sea.

- Padres que puedan identificar a sus hijos en su deseo, que puedan discriminar sus propias necesidades de las de los hijos.

- Que la "cualidad de los padres" facilite el que la identificación con ellos sea permitida y valorada socialmente, para que sean identificaciones sólidas que permitan constituir un sí mismo valioso.

- Capacidad de los adultos de poder organizar una estructura familiar que contenga, que se pueda asumir como buena por los hijos y por los propios adultos.

- Los niños tienen una capacidad enorme de adaptación, pero para ello necesitan padres que les ayuden a elaborar todo ello.

- Promover vínculos de manera muy activa.

\section{CONFLICTO DE INTERESES}

La autora declara no presentar conflictos de intereses en relación con la preparación y publicación de este artículo.

\section{BIBLIOGRAFÍA}

1. Bleichmar S. Subjetividad en riesgo: herramientas para el rescate. Buenos Aires: Topía; 2005.

2. Aulagnier P. Qué deseo, de qué hijo. Revista Psicoanálisis con Niños y Adolescentes. 1992;3:45-9. 